\title{
UJI BANDING BERBAGAI MEDIA TANAM TERHADAP PERTUMBUHAN SELADA MERAH (Lactuca sativa var. crispa L) DENGAN MEDIA TANAM HIDROPONIK SISTEM NFT (Nutrient Film Technique)
}

\author{
G. F. Yanti ${ }^{1)}$ dan Ngadiani ${ }^{2)}$ \\ ${ }^{1)}$ Mahasiswa Prodi Biologi, Fakultas MIPA Universitas PGRI Adi Buana Surabaya \\ ${ }^{2}$ Staf pengajar Prodi Biologi, Fakultas MIPA Universitas PGRI Adi Buana Surabaya \\ e-mail: gadisfransiscayanti95@yahoo.co.id
}

\begin{abstract}
A study has been conducted to compare some varieties of planting media on red lettuce (Lactuca sativa var crispa L), the variables observed in this study are wet weight and chlorophyll content. This research was conducted by using complete randomized design (RAL) consisting of 5 variants of planting medium (Rockwool (as control), cocopeat, fuel husk, cotton and sponge) with 4 replications. The results showed that rockwool planting media had significant effect $(\mathrm{P}<0,05)$ on wet weight of red lettuce plant (Lactuca sativa var. Crispa L). Then, on the results of chlorophyll content test, it was found that the variation of burning husk medium media on red lettuce plant had significant effect $(\mathrm{P}<0,05)$ to chlorophyll $\mathrm{a}$ and total chlorophyll, while in chlorophyll $\mathrm{b}$ the result obtained was not significantly different $(\mathrm{P}>0,05)$. The results of this study indicate that the treatment of rockwool planting media in red lettuce plant growth is effective to increase wet weight and the treatment of burning husk medium media can increase the chlorophyll content of red lettuce plants namely chlorophyll a and total chlorophyll red lettuce plants (Lactuca sativa var. Crispa L.).
\end{abstract}

Keywords: red lettuce, wet weight, test of chlorophyll content a, chlorophyll b, total chlorophyll

\section{PENDAHULUAN}

Permintaan akan komoditas hortikultura terutama sayuran terus meningkat seiring dengan meningkatnya kesejahteraan dan jumlah penduduk. Menurut hasil survai BPS (2001), konsumsi sayuran di Indonesia meningkat dari $31,790 \mathrm{~kg}$ pada tahun 1996 menjadi $44,408 \mathrm{~kg}$ per kapita per tahun pada tahun 1999. Hasil survai tersebut

juga menyatakan bahwa semakin tinggi pengeluaran konsumen, semakin tinggi pengeluaran untuk sayuran per bulannya dan semakin mahal harga rata-rata sayuran per kilogramnya yang mampu dibeli oleh konsumen.

Tanaman selada merah (Lactuca sativa var. crispa L) merupakan salah satu komoditi 
hortikultura yang memiliki prospek dan nilai komersial yang cukup baik. Semakin bertambahnya jumlah penduduk Indonesia serta meningkatnya kesadaran penduduk akan kebutuhan gizi menyebabkan bertambahnya permintaan akan sayuran. Kandungan gizi pada sayuran terutama vitamin dan mineral tidak dapat disubtitusi melalui makanan pokok. Nazaruddin (2003).

Media tanam yang biasa digunakan pada sistem hidroponik adalah rockwoll, yaitu media yang terbuat dari serabut batu apung gunung yang ringan dan mempunyai porositas yang baik, tetapi media tanam dengan rockwoll ini memiliki kelemahan yaitu sulit diperoleh dan harganya yang relatif mahal. Sebagai alternatif pengganti rockwool dapat menggunakan bahan-bahan lain yang memiliki porositas yang baik sebagai media.

Media cocopeat adalah bahan sisa setelah serat telah dihapus dari kulit terluarnya dari kelapa. Coconut Coir bersimbiosis dengan jamur Trichoderma, yang berfungsi sebagai melindungi akar dan merangsang pertumbuhan akar. Menurut Tim Penulis PS (2009), sekam bakar adalah media tanam yang porous dan steril dari sekam padi yang hanya dapat dipakai untuk satu musim tanam dengan cara membakar kulit padi kering di atas tungku pembakaran, dan sebelum bara sekam menjadi abu disiram dengan air bersih. Hasil yang diperoleh berupa arang sekam (sekam bakar). Selanjutnya Yati Supriati dan Ersi Herliana (2011) mengemukakan arang sekam adalah sekam padi yang telah dibakar dengan pembakaran tidak sempurna. Cara pembuatannya dapat dilakukan dengan menyangrai atau membakar. Kemudian media tanam kapas dapat menjaga kelembapan yang lebih lama dan lebih baik dari pada media tanah. Selain itu tekstur kapas yang lembut sangat cocok untuk akar tanaman.

\section{MATERI DAN METODE}

Penelitian ini dilakukan menggunakan percobaan rancangan acak lengkap yang terdiri atas 5 perlakuan media tanam M0 (Media Rockwool), M1 (Media Cocopeat), M2 (Media Sekam Bakar), M3 (Media Kapas), M4 (Media Spons) dengan 4 kali ulangan. Penelitian ini dilaksanakan pada bulan Maret Mei 2017 di Green House dan Laboratorium FMIPA UNIPA Surabaya.

\section{ALAT DAN BAHAN \\ Bahan-bahan yang digunakan dalam penelitian ini meliputi biji tanaman selada merah (Lactuca sativa L. var. crispa), media tanam cocopeat, sekam bakar, kapas, spons dan larutan nutrisi $\mathrm{AB}$ mix.}


Alat-alat yang digunakan dalam penelitian ini meliputi peralatan instalasi NFT, tray semai, drum nutrisi, termometer, $\mathrm{pH}$ meter, EC meter (electro conductivity meter), gelas ukur, pengaduk larutan, timbangan analitik, penggaris, netpot.

Pembuatan

Kontruksi Hidroponik NFT (Nutrient Film Technique)

Dirancang

konstruksi

hidroponik NFT dengan ukuran dan ketentuan yang telah ditetapkan. Kemudian letakkan drum nutrisi pada posisi sejajar dengan ketinggian minimum dari ujung outlet talang. Dipasang pipa lateral yang dilengkapi selang plastik sebagai inlet pada drum nutrisi. Kemudian dipasang pipa penampung dengan posisi miring yang dilengkapi dengan selang plastik sebagai outlet. Didirikan atap plastik. Lalu pada salah satu kaki atap dilengkapi thermometer bola kering dan dan bola basah.

\section{Pembuatan Larutan Nutrisi Ab-} Mix

Pembuatan pupuk hidroponik AB-Mix vegetative merupakan ramuan pupuk untuk kelompok tanaman vegetative. Pupuk tersebut mengandung total N $200 \mathrm{ppm}$ dengan rasio 7 antara nitrat dan ammonium. Pupuk dibuat dengan mencampur 500 gram pupuk $\mathrm{A}$ dilarutkan dengan air sampai volume mencapai $500 \mathrm{ml}$. Pembuatan pupuk B, sebanyak 500 gram pupuk B dilarutkan dengan air sampai volume mencapai $500 \mathrm{ml}$. Kemudian pada proses pencamuran, sebanyak $5 \mathrm{ml}$ pupuk A dan $5 \mathrm{ml}$ pupuk B ditambahkan kedalam bak penampung nutrisi dan ditambahkan air sampai volume mencapai 1 liter.

\section{Persemaian}

Proses penyemaian biji dapat dilakukan dengan cara melakukan sortir biji. Kemudian siapkan bak tray semai yang telah diisi cocopeat, sekam bakar, kapas, spons untuk penyemaian selada merah. Lalu lubangi rockwool dengan pakucin, kemudian meletakan benih tanaman selada merah yang telah lolos penyortiran kedalam rockwoll. Setelah itu lakukan penyiraman pada media tanam rockwool, cocopeat, sekam bakar, kapas dan spons yang berisi benih tanaman selada merah dengan air biasa yang telah diukur kadar $\mathrm{pH}$ air sebelumnya. Penyemaian dilakukan selama 7 hari atau telah memiliki 34 daun, serta perakaran berkembang dengan baik dan kontrol proses pertumbuhanya, letakkan semaian di dalam Green house dengan penyinaran cahaya matahari yang cukup. 


\section{Penanaman}

Benih yang telah berkecambah atau bibit selada merah umur 7-8 HSS sudah dapat dipindahkan ke netpot atau instalasi hidroponik $\mathrm{nft}$ untuk proses peremajaan.

\section{Pengujian Jumlah Klorofil}

Klorofil total daun diukur dengan menggunakan spectrofotometer dengan menggunakan metode International Rice Research Institute (IRRI) yang telah dimodifikasi oleh Balitbo Bogor (Alsuhendra,2004; Nurdin, 2009 dalam KA Prasetyo 2015).

Daun segar dipotong kecilkecil, ditimbang $0,1 \mathrm{~g}$ dan digerus hinggá halus sambil ditambahkan aseton $80 \%$ sebanyak $2 \mathrm{ml}$. Hasil gerusan dimasukkan dalam tabung untuk disentrifugasi pada kecepatan $3.000 \mathrm{rpm}$ selam 10 menit, kemudian diencerkan dengan aquades hingga $5 \mathrm{ml}$. Kandungan klorofil contoh siap untuk diukur dengan menggunakan spektrofotometer UV-Vis pada panjang gelombang 663 dan 645 $\mathrm{nm}$. Kadar klorofil dihitung dengan menggunakan rumus $(\mathrm{mg} / \mathrm{L})=20.2$ A $645.0 \mathrm{~nm}+8.02$ A $663.0 \mathrm{~nm}$.

\section{Pengukuran Berat Basah Selada Merah}

Pengukuran berat basah dari tanaman selada merah dapat dilakukan dengan menimbang sampel tanaman yang telah dipanen menggunakan timbangan analitik kemudian hasil pengukuran dicatat dalam tabel pengukuran berat basah.

\section{Analisis Statistika}

Analisis data dilakukan secara kuantitatif yaitu dengan analisis varian (Anava) satu jalur dengan perangkat lunak SPSS. Langkah pertama yaitu melakukan uji homogenitas pada data yang tersedia. Setelah data teruji homogen dianalisis menggunakan analisis varian satu arah rancangan acak lengkap pada taraf signifikan 0,05 .

\section{HASIL DAN PEMBAHASAN Bobot Basah}

Hasil penelitian (Gambar 4.1) menunjukkan bahwa penggunaan beberapa jenis media tanam berpengaruh signifikan $(\mathrm{P}<0,05)$ terhadap bobot basah tanaman selada merah. 


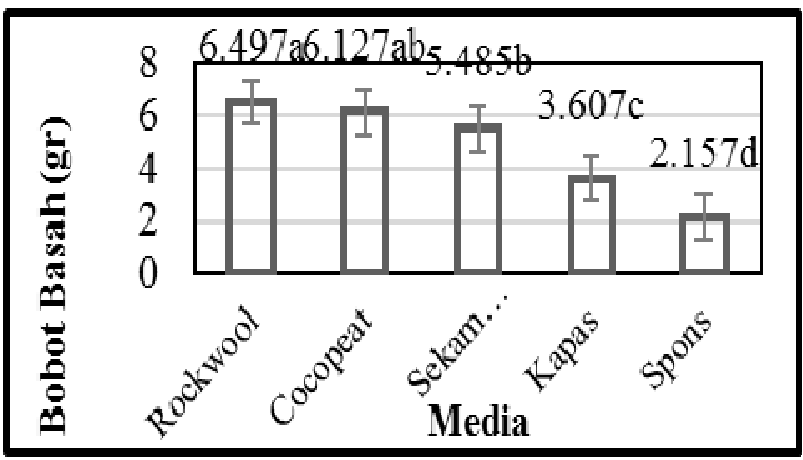

Gambar 4.1. Bobot basah selada merah (Lactuca sativa) yang ditumbuhkan pada berbagai media tanam dengan sistem hidroponik, angka yang diberi huruf $(\mathrm{a}$ dan $\mathrm{b}$ ) tidak sama menunjukkan berbeda signifikan $(\mathrm{P}<0,05)$

Bobot basah tanaman selada merah (Lactuca sativa var. crispa L.) yang menggunakan media tanam rockwool (kontrol) $(6.497 \pm$ $0,24 \mathrm{~g})$ signifikan $(\mathrm{P}<0,05)$ lebih tinggi dibandingkan media tanam cocopeat (M1) $(6.127 \pm 0,22 \mathrm{~g})$, sekam bakar (M2) $(5.485 \pm 0,31 \mathrm{~g})$, kapas (M3) (3.607 $\pm 0,39 \mathrm{~g})$, dan spons (M4) (2.157 $\pm 0,40 \mathrm{~g})$. Hasil rerata bobot basah tanaman selada merah (Lactuca sativa var. crispa perlakuan media tanam (kontrol) yang menggunakan media tanam rockwool $(6.497 \pm 0,24 \mathrm{~g})$.

\section{Kandungan Klorofil A}

Hasil penelitian pada gambar 4.2. menunjukkan bahwa perlakuan beberapa jenis media tanam tidak berbeda signifikan $(\mathrm{P}>0,05)$ terhadap bobot basah tanaman selada merah (Lactuca sativa var. crispa $\mathrm{L}$ ).

L.) tertinggi terletak pada

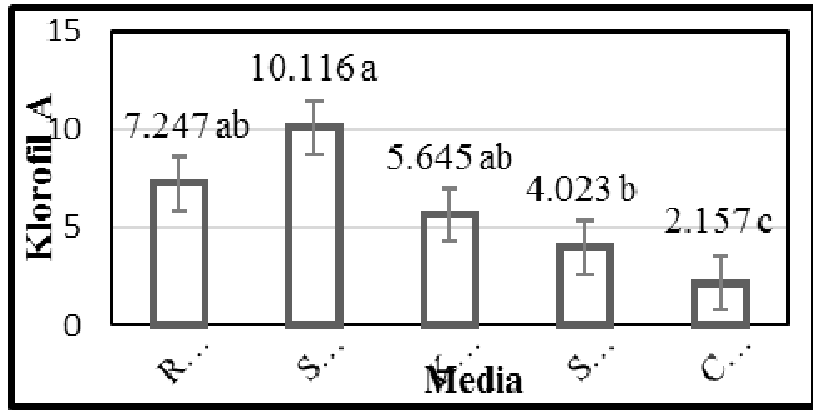

Gambar 4.2. Rata-rata klorofil a selada merah (Lactuca sativa var. Crispa L) yang tumbuh pada berbagai media tanam dengan sistem hidroponik, angka yang diberi huruf a menunjukkan bahwa tidak berbeda signifikan $(\mathrm{P}>0,05)$. 
Klorofil a pada tanaman selada merah (Lactuca sativa var. crispa L.) yang menggunakan perlakuan media tanam sekam bakar $\quad(10.116 \pm 0,22 \mathrm{~g} / \mathrm{ml})$ signifikan $(\mathrm{P}<0,05)$ lebih tinggi dibandingkan rata-rata yang menggunakan perlakuan media tanam cocopeat $(2.157 \pm 0,40 \mathrm{~g} / \mathrm{ml})$, namun tidak berbeda signifikan $(\mathrm{P}>0,05)$ dengan rata-rata jumlah klorofil a yang menggunakan perlakuan media tanam rockwool $(7.247 \pm 0,24 \mathrm{~g} / \mathrm{ml})$ dan kapas (5.645 $\pm 0,31 \mathrm{~g} / \mathrm{ml})$. Berdasarkan hasil yang didapatkan rata-rata kandungan klorofil a yang tertinggi pada tanaman selada merah (Lactuca sativa var. crispa L.) terletak pada media tanam sekam bakar $(10.116 \pm 0,22 \mathrm{~g} / \mathrm{ml})$.

\section{Klorofil B}

Hasil penelitian pada gambar 4.3. menunjukkan bahwa perlakuan beberapa jenis media tanam tidak berbeda signifikan $(\mathrm{P}>0,05)$ terhadap kandungan klorofil tanaman selada merah (Lactuca sativa var. crispa $\mathrm{L}$ ).

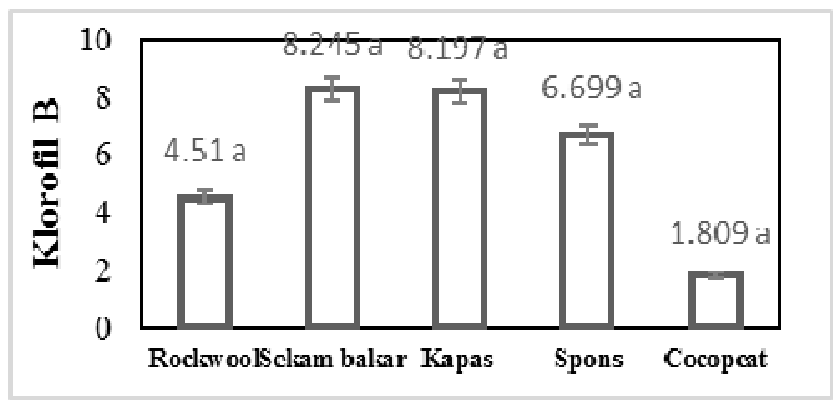

Gambar 4.3. Rata-rata klorofil b pada tanaman selada merah Lactuca sativa var. Crispa $L$ ) yang ditumbuhkan pada berbagai media tanam dengan sistem hidroponik yang diberi notasi huruf sama menunjukkan tidak berbeda signifikan $(\mathrm{P}>0,05)$.

Rata-rata jumlah klorofil b pada tanaman selada merah (Lactuca sativa var. crispa L.) yang menggunakan media tanam rockwool (kontrol) $(4.51 \pm 1,638$ $\mathrm{g} / \mathrm{ml})$,), sekam bakar (M2) (8.245 \pm $1,296 \mathrm{~g} / \mathrm{ml})$, kapas (M3) $(8.197$ $\pm 1,551 \mathrm{~g} / \mathrm{ml})$, dan spons (M4) $(6.699 \pm 8,242 \mathrm{~g} / \mathrm{ml})$, cocopeat (M1) $(1.809 \pm 0,590 \mathrm{~g} / \mathrm{ml})$ menunjukkan bahwa tidak berbeda signifikan $(\mathrm{P}>0,05)$.

\section{Klorofil Total}

Hasil penelitian pada gambar 4.4 menunjukkan bahwa perlakuan beberapa media tanam berpengaruh signifikan $\quad(\mathrm{P}<0,05) \quad$ terhadap klorofil total tanaman selada merah (Lactuca sativa var. crispa L). 


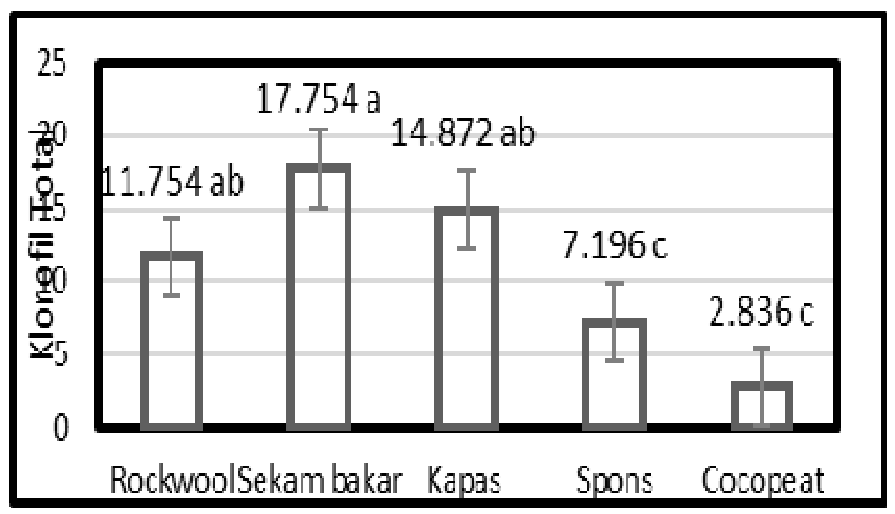

Gambar 4.4 Rata-rata Klorofil Total (mg/g) Tanaman Selada Merah (Lactuca sativa var. crispa $\mathrm{L}$ ) pada berbagai jenis media tanam, maka diberi huruf ( $\mathrm{a}, \mathrm{b}$ dan c) tidak sama menunjukkan berbeda signifikan $(\mathrm{P}<0,05)$.

Klorofil total pada tanaman selada merah (Lactuca sativa var. crispa L.) yang menggunakan perlakuan media tanam sekam bakar $(17,754 \quad \pm 6,978 \quad \mathrm{~g} / \mathrm{ml}) \quad$ signifikan $(\mathrm{P}<0,05)$ lebih tinggi dibandingkan rata-rata yang menggunakan perlakuan media tanam cocopeat $(2.836 \pm 1,072 \mathrm{~g} / \mathrm{ml})$, namun tidak berbeda signifikan $(\mathrm{P}>0,05)$ dengan rata-rata jumlah klorofil total yang menggunakan perlakuan media tanam rockwool $(11.754 \pm 1,072$ $\mathrm{g} / \mathrm{ml})$ dan kapas $(14.872 \pm 2,249$ $\mathrm{g} / \mathrm{ml}$ ). Berdasarkan hasil yang didapatkan rata-rata kandungan klorofil total yang tertinggi pada tanaman selada merah (Lactuca sativa var. crispa L.) terletak pada media tanam sekam bakar $(17,754$ $\pm 6,978 \mathrm{~g} / \mathrm{ml})$.

\section{PEMBAHASAN \\ Bobot Basah}

Pada hasil yang telah dilakukan menunjukkan bahwa penggunaan bebagai jenis media tanam berpengaruh signifikan $(\mathrm{P}<0,05)$ terhadap pertumbuhan tanaman selada merah. Hal tersebut dapat disebabkan oleh beberapa factor yang dapat memengaruhi perkembangan tanaman antara lain yaitu media tanam yang baik bagi tanaman dan lingkungan tempat menanam.

Pada pengukuran bobot panen selada merah didapatkan hasil ratarata bobot tertinggi terletak pada perlakuan kontrol yaitu dengan menggunakan media tanam rockwool. Pada penggunaan berbagai jenis media tanam hasil yang didapat tidak terlalu tinggi terutama pada media tanam spons yang memiliki bobot tanaman selada 
paling rendah. Hal ini disebabkan karena sifat rockwool yang ideal sebagai media tumbuh pada sistem hidroponik. Rockwool merupakan media yang bersifat inert, sedikit alkalin dan tidak menyebabkan degradasi biologi. Media ini memiliki ruang pori sebesar $95 \%$ dengan daya pegang air sebesar $80 \%$ (Resh, 1998). Jadi hasil bobot basah selada merah tertinggi terdapat pada media tanam rockwool.

\section{Kandungan Klorofil}

Berdasarkan hasil penelitian yang telah dilakukan mengindikasi bahwa menggunakan berbagai jenis media tanam berpengaruh signifikan $(\mathrm{P}<0,05)$ terhadap kandungan klorofil salada merah (Lactuca sativa var. crispa $\mathrm{L}$ ). Hal ini terbukti dengan adanya jumlah rata-rata tertinggi klorofil a dan klorofil total terletak pada perlakuan sekam bakar.

Pertumbuhan dan perkembangan tumbuhan

dipengaruhi oleh faktor eksternal dan internal. Faktor-faktor eksternal utama adalah tanah, kelembaban, cahaya dan air. Faktor-faktor internal dapat mencakup gen, hormon, struktur anatomi dan morfologi organ tumbuhan serta kandungan klorofil dan pigmen lainnya (Lakitan, 2001). Senyawa klorofil merupakan senyawa yang cukup peka terhadap perubahan cahaya, temperatur, $\mathrm{pH}$, dan oksigen. Senyawa klorofil akan bekerja stabil dalam menunjukkan warna hijau pada rentang temperatur kamar hingga $10^{\circ} \mathrm{C}$ dan pada $\mathrm{pH}$ sekitar netral (7 - 8). Pada $\mathrm{pH}$ asam (3 - 5) dan pH basa (11 - 12) klorofil mengalami reaksi dan menghasilkan berbagai senyawa turunan klorofil.

Klorofil a berperan secara langsung dalam reaksi pengubahan energi radiasi menjadi energi kimia serta menyerap dan mengangkut energi ke pusat reaksi molekul. Sementara itu, klorofil $b$ berfungsi sebagai penyerap energi radiasi yang selanjutnya diteruskan ke klorofil a. Salah satu bentuk adaptasi secara fisiologis tanaman terhadap penyinaran rendah adalah dengan penurunan rasio klorofil $\mathrm{a} / \mathrm{b}$ melalui peningkatan klorofil $b$. Meningkatnya klorofil $b$ berdampak positif terhadap efektivitas penyerapan energi radiasi pada kondisi yang ternaungi. Menurut Rotundo et al. (2004) salah satu karakteristik penyesuaian terhadap penyinaran rendah akibat adanya naungan adalah peningkatan kandungan klorofil daun. Peningkatan ini berhubungan dengan bertambahnya kompleks pemanenan cahaya (Light Harvesting Complex II) serta membesarnya antena pada fotosistem II yang mengakibatkan efisiensi penangkapan cahaya meningkat. 
Pada tanaman selada merah daun yang dihasilkan memiliki warna hijau dan hanya terdapat semburat warna merah. Hal ini disebabkan karena Kandungan pigmen antosianin pada daun yang berwarna hijau tua ternyata lebih besar daripada kandungan pigmen antosianin pada daun yang berwarna merah. Hal ini dikarenakan daun hijau adalah daun yang paling dominan dan daun ini merupakan daun yang paling tua dan tumbuh diawal, sehingga kadar pigmen pigmen lain dan juga pigmen antosianin cukup besar pada daun yang berwarna hijau daripada daun yang berwarna merah.

Tetapi kandungan pigmen antosianin ini tidak lebih besar dari kandungan klorofil, termasuk pada daun yang berwarna merah. Baik pada daun yang berwarna hijau maupun pada daun yang berwarna merah, kandungan antosianinnya lebih rendah dan kandungan klorofilnya lebih tinggi. Hal ini dikarenakan klorofil merupakan pigmen utama yang ada pada seluruh tanaman, sehingga meskipun daunnya berwarna merah, tidak berarti bahwa daun tersebut memiliki pigmen antosianin yang dominan, tetapi pigmen yang dominan tetap klorofil.

\section{SIMPULAN DAN SARAN Simpulan}

1. Menggunakan varian media tanam berpengaruh signifikan untuk meningkatkan bobot basah dan untuk meningkatkan kandungan klorofil pada tanaman selada merah (Lactuca sativa var. crispa)

2. Media yang memberikan hasil terbaik yaitu :

a. Media rockwool dapat berpengeruh terhadap berat basah terbaik pada hidroponik sistem NFT

b. Media tanam sekam bakar berpengarruh terhadap klorofil A dn Klorofil Total

\section{Saran}

Perlu adanya penelitian lanjutan untuk mengetahui beberapa jenis media tanam yang lebih baik agar mendapatkan hasil tanaman selada merah (Lactuca sativa var. crispa) yangb baik. Saran yang selanjutnya adalah pada saat menentukan jenis tanaman yang akan diteliti harus disesuaikan dengan keadaan green house. Kemudian saran yang terakhir adalah perlu adanya uji kandungan antosianin. 
DAFTAR PUSTAKA

Alsuhendra. (2004). Daya AntiAtherosclerosis Zn-Turunan Klorofil Dari Daun Singkong (Manihot Esculenta Crantz) Pada Kelici Percobaan. Unpublished $\mathrm{PhD}$ thesis, Program Pascasarjana, Institut Pertanian Bogor. (dalam KA Prasetyo 2015)

Lakitan B, 2001 Dasar-Dasar Fisiologi Tumbuhan, Raja Grafindo Persada, Jakarta.

Nazaruddin, 2003. Budidaya dan Pengaturan Panen Sayuran Dataran Rendah.Penebar Swadaya. Jakarta.

Nurdin, Kusharto, C. M., tanziha, I., \& Januwati, M, (2009). Kandungan klorofil berbagai jenis daun tanaman dan $\mathrm{Cu}$ turunan klorofil serta karateristik fisiko-kimia, 4(1),
13-19 (dalam KA Prasetyo 2015).

Penulis PS.Budidaya Tomat Secara Komersial.Penebar Swadaya. Jakarta. 2009.

Resh, H.M. 1998. Hydroponic Food Production. Santa Barbara. Woodbridge Press.

Rotundo, A., M. Forlani and C. Di Vaio. 2004. Influence of shading net $n$ negative and productive characteristics, gas exchange and chloropyll content of the leaves in tho blackberry (Rubus ulmifolius Schott). (serial on line). http:/ www.actahort.org/books/457/4 57-42.htm

Supriati, Yati dan Herliana, Ersi .2011. Bertanam 15 Sayuran Organik Dalam Pot. Penebar Swadaya. Jakarta. 